\title{
The Study Related to the Execution of a Triangulation Network in the Dump of Rovinari Pit, in Order to be Restored to the Economic Circuit
}

\author{
George POPESCU ${ }^{*}$, Cosmin - Alin POPESCU ${ }^{1}$, Mihai HERBEI ${ }^{1}$, Lucian DRAGOMIR ${ }^{1}$ \\ ${ }^{1}$ Banat's University of Agricultural Sciences and Veterinary Medicine, Faculty of Agriccultural Sciences, \\ Timisoara, Aradului Street, no. 119, R0 300645, Romania \\ *)Corresponding author, e-mail: popescu.george25@yahoo.com
}

BulletinUASVM Horticulture 73(2) / 2016

Print ISSN 1843-5254, Electronic ISSN 1843-5394

DOI:10.15835/buasvmcn-hort:12184

\begin{abstract}
The lignite mining extraction within the mining perimeter in Rovinari is carried out through mining works in the open, by using large equipments for the excavation, transport and storage of the mining material. These surfaces are currently being set up in the area of level two of the dump, the west and north-west part of Rovinari pit. In order to carry out the set-up works and of follow-up of the stability of the pit levels it is necessary to maintain the triangulation network.
\end{abstract}

Keywords: design, geodesic network. measurement, mining basin

\section{INTRODUCTION}

In the mining area Rovinari, the daily activity of lignite extraction is executed by using machines with high capacity for excavation, transport and storage of the mining masses. The perimeter of Rovinari quarry covers an area of meadow, whose operation has been completed and a hilly area. Currently coal mining activity takes place in hilly and tailings waste dumping is done in the exploited area of floodplain.

In the period 1969-1970, with the entry into operation of high capacity equipment, work continued through the trench opening in the western perimeter of exploitation, where the ratio of layer overburdening presents the lowest values.

Since 1990, excavation of the quarry fronts entered the hilly perimeter, requiring readjustment work steps depending on the terrain. Quarry advancement was made in a fan shape with work fronts moving on the northern side of mining field, where the ratio of overburdening is the worst.
Since 1990, when excavation fronts reached and advanced in the hilly area at Rovinari career, the question of refunding the land for the silvic circuit was taken into account having the objective of reforestation.

Currently, these areas are arranged in the stage two landfill, west and northwest Rovinari quarry.

For execution of planning and tracking stability landfill steps necessary maintenance of the triangulation network. (Popescu G., 2012)

\section{MATERIALS AND METHODS}

The reserve perimeter is part of the Rovinari Motru - Jiu coal basin, located in the northern half of the Depression Getic.

Rovinari quarry dump area is comprised of two distinct forms of landforms:

- Jiu River floodplain between the western boundary of the heap indoor and former national road DN 66, on its old location: 


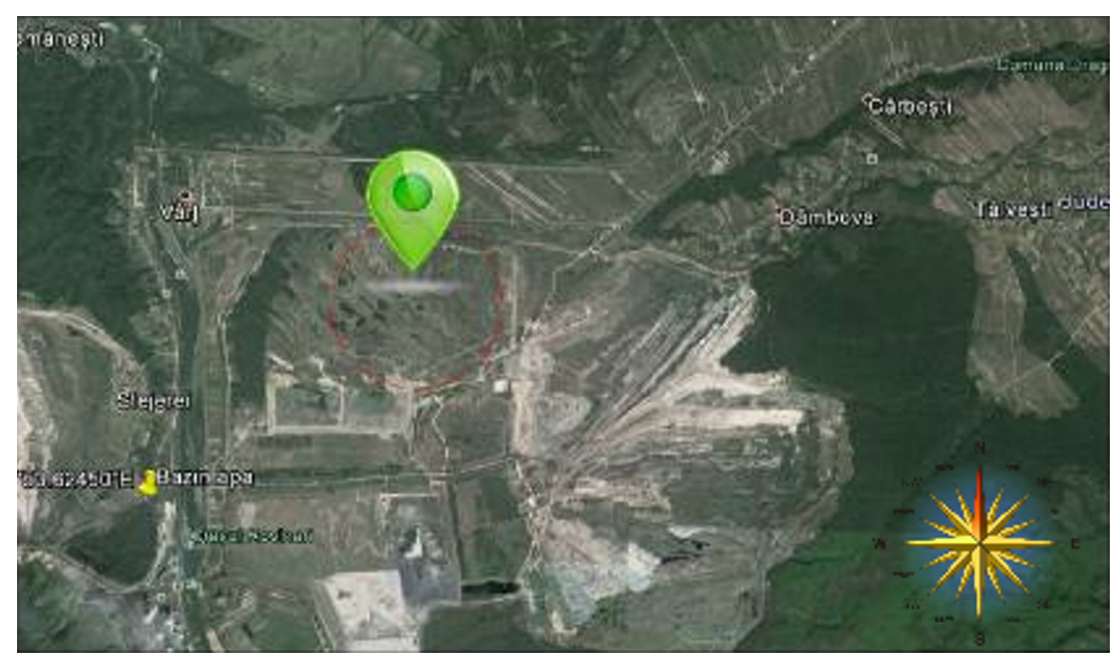

Fig.1. Locating objective - dump - Rovinari quarry

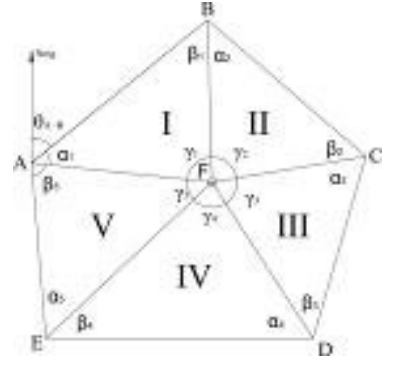

Fig. 2. Central point polygon with normal and short basis



Fig. 3. Polygon chain with one central point

- The hilly area, east of the mentioned road, characterized by an alternation of valleys and hills that determine a difference in levels height of $30-55 \mathrm{~m}$ and a total height of 25-101 m of the quarry.

The main valleys that cross the quarry perimeter are Dambovita Valley and Corbu Valley. These valleys present permanent water afluents and require hydraulic works for their deviation from the mining field. The quarry dump area is located in the Rovnari coal basin, Gorj county, 15 $\mathrm{km}$ south of Tg. Jiu, in the hilly area of eastern Jiu River and bounded as follows:

- to the North: the C.F.R. Tg. Jiu - Rogojelu and Cârbești town;

- in the south of the former slag deposit Balta Uchiasului quarry and Gârla-Corbului fault that limits the conventional East-Rovinari quarry;

- in the east, the deposit with difficult conditions, where the layers of lignite thickness shrinks below its exploitation.

- in the west the river Jiu course which regularized.

Exploatation perimeter outline was defined depending on the conditions of the deposit, the land configuration, the ratio of overburdening works resulting from prospecting and surface targets in areas adjacent to existing mining field (Fig.1).

Topographical works executed consists in materializing the objectives specified in the project of topographical mapping networks.

The determination will be done by the coordinate point variation method using triangulation points relevant to the mining field in E.M. Rovinari, Rovinari quarry.

The density of the geodesic points is in general in between 1 and $60 \mathrm{~km}$, but not all the network points are part of the same category. They are grouped in five "orders", among whom there are 3 ( I,II and III) are called "superior orders" and the last two ( IV and V) are called "inferior orders".

Each of these "orders" is grouping points which are situated at the same distance each one from another, such as:

- first type network are formed by points with distance between app. 20-60 km;

- second type network are formed by points with distance between app. 10-20 km 


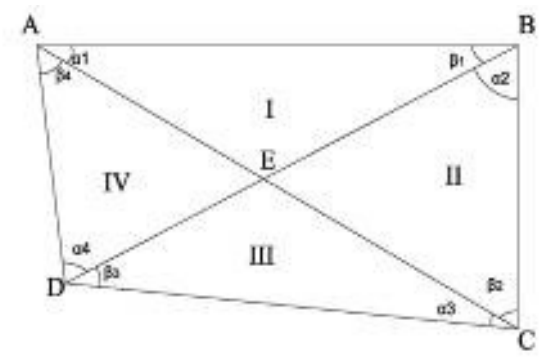

Fig. 4. Quadrilateral with diagonals with normal basis and short basis



Fig. 5. Quadrilateral chain



Fig. 6. Traingles chain



Fig. 7. Central point polygon - with normal and short basis

- third type are formed by points with distance - between 1-2 km, such as 500-1000 m (Dima N. et between app. 3-10 km

- the inferior types of network such as IV and V are al., 2005, 2006, 2010; Neuner J, 2000)

formed by points with distance

Main types of local triangles network are showen in: Fig. 2, Fig. 3, Fig. 4, Fig. 5, Fig. 6 




Fig. 8. Geodetic network support - landfills, Rovinari quarry

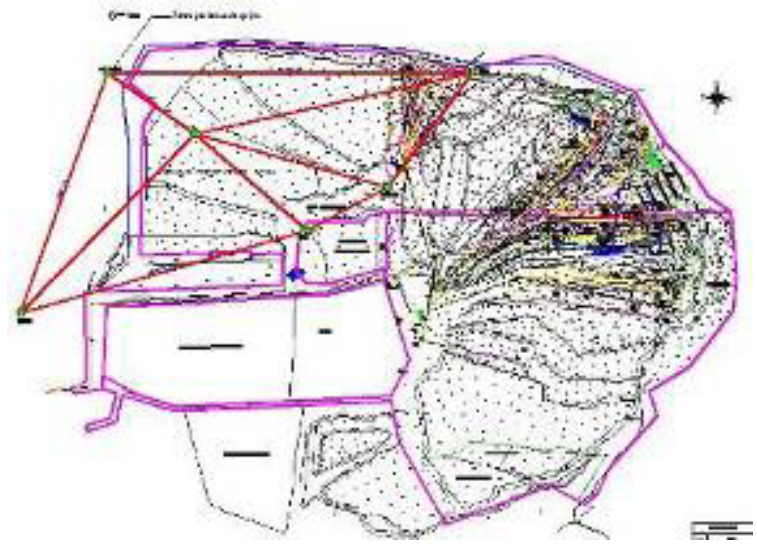

Fig. 9. Situation plan

Geodetic network support - landfills Rovinari quarry



Fig. 10. Geodetic network overlay on topographic plan

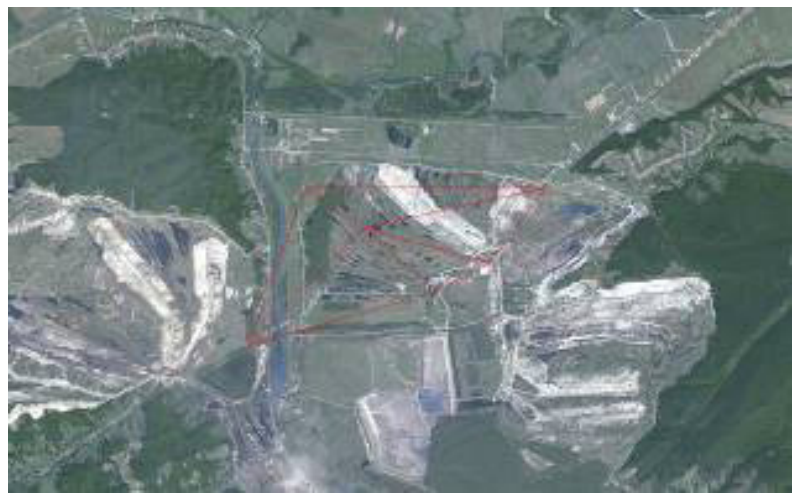

Fig. 11. Geodetic network overlay on orthophotomap

\section{RESULTS AND DISCUSSION}

Analyzing on plan and completing a field reconnaissance was chosen for the triangulation a number of 6 triangulation points belonging to the state triangulation and forming a polygon with a central point (Fig7).

Carrying out further otpographic operations were carried out by the following steps:
1. Measurements were made in the geodetic network and consists of the following:

1.1 Measurements of horizontal angles between points of triangulation;

1.2 Measurements of vertical angles between points of triangulation;

1.3 Application of triangulation points to the materialized point; 
Tab.1. A comparative table of coordinates

\begin{tabular}{|c|c|c|c|c|c|c|c|c|c|}
\hline \multirow{3}{*}{ Name points } & \multicolumn{4}{|c|}{ Coordinate offset } & \multicolumn{4}{|c|}{ Old geodetic coordinate points } & \multirow{3}{*}{$\begin{array}{l} \pm \Delta X \\
\pm \Delta Y\end{array}$} \\
\hline & \multicolumn{2}{|c|}{$\mathrm{X}$} & \multicolumn{2}{|c|}{$\mathrm{Y}$} & \multicolumn{2}{|c|}{$\mathrm{X}$} & \multicolumn{2}{|c|}{$\mathrm{Y}$} & \\
\hline & $\mathrm{m}$ & $\mathrm{mm}$ & $\mathrm{m}$ & $\mathrm{Mm}$ & $\mathrm{m}$ & $\mathrm{mm}$ & $\mathrm{m}$ & $\mathrm{Mm}$ & \\
\hline \multirow{2}{*}{ Colonie Vârț } & \multirow{2}{*}{ - } & \multirow{2}{*}{-} & \multirow{2}{*}{ - } & \multirow{2}{*}{ - } & \multirow{2}{*}{384249} & \multirow{2}{*}{037} & \multirow{2}{*}{353414} & \multirow{2}{*}{409} & - \\
\hline & & & & & & & & & - \\
\hline \multirow{2}{*}{ CFR } & \multirow{2}{*}{384252} & \multirow{2}{*}{297} & \multirow{2}{*}{356693} & \multirow{2}{*}{788} & \multirow{2}{*}{384252} & \multirow{2}{*}{298} & \multirow{2}{*}{356693} & \multirow{2}{*}{789} & $-0,001$ \\
\hline & & & & & & & & & $-0,001$ \\
\hline \multirow{2}{*}{ Dispecer } & \multirow{2}{*}{383224} & \multirow{2}{*}{826} & \multirow{2}{*}{355931} & \multirow{2}{*}{024} & \multirow{2}{*}{383224} & \multirow{2}{*}{810} & \multirow{2}{*}{355931} & \multirow{2}{*}{036} & $+0,016$ \\
\hline & & & & & & & & & $-0,012$ \\
\hline \multirow{2}{*}{ Gegău } & \multirow{2}{*}{382840} & & & & & & & & $-0,015$ \\
\hline & & 707 & 355210 & 274 & 382840 & 722 & 355210 & 268 & 0,006 \\
\hline & & & & & & & & & 0,011 \\
\hline Bazın Apã & 382100 & 252 & 35 & 168 & 00 & 241 & 352 & 184 & $-0,016$ \\
\hline $\mathrm{B}$ & 383702 & 782 & 354 & 130 & 383702 & 791 & 354198 & 136 & $-0,009$ \\
\hline D & $303 / 02$ & 102 & 334 & 130 & $383 / 02$ & 191 & 334190 & 130 & $-0,006$ \\
\hline
\end{tabular}

1.4 Measuring the signal height and instrument height at every point of triangulation;

1.5 Measurements of height differences and distances carried by geodetic leveling in between(at the middle), closed, starting from point A of triangulation.

2. Processing of the measured values within geodetic network will consist of:

2.1 As known, triangulation point A coordinates and based on measurements taken coordinates of other points of triangulation were determined through the method of conditional measurements. This method was chosen because the network has a simple geometric form, a polygon with a center point, and the number of known points is small.

2.2 Solving the leveling of the triangulation network. Based on measurements, level points of the triangulation network were determined by trigonometric-geodesic leveling starting point "Gegău" of which its level height was known. The processing of the measured values were carried out by means of indirect measurements, namely: the successive approximations method. This method was chosen because it is a rigorous method of calculation and does not require a large amount of calculation.

2.3 Determination of point A coordinates. The coordinates of point A was determined using the indirect method, namely the method of coordinates variation. This method was chosen because the known points are in large numbers, the method is rigorous the volume of computing is small.

2.4 Determination of assigned level points. Points level heights were determined by trigonometric leveling method because this removes some measurement errors, the is most accurate method used for this purpose.

The compensation of the geodetic support network is shown in the following figures (Fig.8., Fig.9, Fig.10. Fig.11):

Following this network compensation the following results were achieved (Tab.1):

\section{CONCLUSION}

Networks and topographic surveying of mining basins are designed to create the support foundation for all works running in this sector. Depending on the quality of these networks, expressed through the accuracy of the geodetic and topographical points, further surveying and topographical works are carried out destined to design, exploitation of mineral resources, the effective investment as well as works for cadastral records of the patrimony, and in some cases special tracking of their behavior in time (ie. waste deposits).

Any negligence in performing surveying and topographical work can have particularly serious consequences in investments, resulting in extreme 
cases with unwanted accidents and costly repairs or modifications.

To improve the efficiency of measurement, in close correlation with the implementation, it must employ professionals with modern measuring equipment (GNSS technology) enabling the storage and transmission of measured data to stations processed by modem or fiber optic cable.

\section{REFERENCES}

1. Dima N, Herbei $O$ (2005). Topografie generală şi elemente de topografie minieră. Ed. Universitas, Petroşani.

2. Dima N (2006). Geodezie. Ed. Universitas.

3. Dima N, Popescu G (2011). Monitoring the phenomenon of displacement and surface deformation using topographical methods at Livezeni Mine, Proceeding of the $11^{\text {th }}$ International Multidisciplinary Scientific GeoConference \& EXPO, SGEM, Bulgaria.

4. Neuner J. (2000). Sisteme de poziționare globală, Ed. MatrixROM, Bucureşti.

5. Popescu G (2012). Improving current methods of monitoring the surface movement in mining areas. Doctoral dissertation, Petrosani. 